\title{
Pesti des petits ruminants virus infection in animals
}

\author{
Chauhan $\mathrm{H} \mathrm{C}^{1}$, Chandel B S ${ }^{2}$, Kher $\mathrm{H} \mathrm{N}^{3}$, Dadawala A I ${ }^{4}$ and Agrawal S M${ }^{5}$ \\ Department of Microbiology, \\ College of Veterinary Science and AH, SDAU, Sardarkrushinagar- 385506 (BK), Gujarat
}

\begin{abstract}
For centuries morbillivirus infections have had a huge impact on both human beings and animals. Morbilliviruses are highly contagious pathogens that cause some of the most devastating viral diseases of humans and animals world wide. They include measles virus (MV), canine distemper virus (CDV), rinderpest virus (RPV) and peste des petits ruminants (PPRV) virus. Furthermore, new emerging infectious diseases of morbilliviruses with significant ecological consequences of marine mammals have been discovered in the past decades. Phocid distemper virus (PDV) in seals and the cetacean morbillivirus (CMV) have been found in dolphins, whales and porpoises. Peste des petits ruminants (PPR) is a highly contagious, infectious, an acute or sub acute viral disease of domestic and wild small ruminants characterized by fever, oculonasal discharges, stomatitis, conjunctivitis, gastroenteritis and pneumonia. Goats are more severely affected than sheep. It is also known as pseudorinderpest of small ruminants, pest of small ruminants, pest of sheep and goats, kata, stomatitis- pneumoentritis syndrome, contagious pustular stomatitis and pneumoentritis complex. It is one of the major notifiable diseases of the World Organization for Animal Health (OIE).

Keywords: Ruminant, Infection, Animal, Virus, Incubation, Ruminant, Economic, Emerging Disease.
\end{abstract}

\section{Epidemiology and Geographic Distribution}

PPR was first described in Côte d'Ivoire (Gargadennec L. \& Lalanne A., 1942) and then after, it has been recognized in many of the sub-saharian countries that lie between the Atlantic Ocean and the Red Sea (Lefevre and Diallo, 1990). The affected area extends north to Egypt and south to Kenya, in EasternAfrica, and to Gabon, in Western-Africa. PPR has not been recognized in most of Northern and SouthernAfrica. In 1998, serological survey in the United Republic of Tanzania did not detect any antibodies to PPR suggesting that infection has not extended that far to the south. PPR is present in nearly all Middle Eastern countries up to Turkey (Furley et al.. 1987; Lefevre et al. 1991; Perl et al. 1994; Taylor et al. 1990, Ozkul et al. 2002). It is also widespread in India and southwest Asia (Shaila et al. 1989).

Presently, PPR occurs in most African countries situated in a wide belt between the Sahara and equator, the middle east ( Arabian peninsula, Israel, Syria and Jordon) and the Indian subcontinent. Outbreaks of PPR are now known to be common in India, Nepal, Bangladesh, Pakistan and Afghanistan ( Abdollahpour et al, 2006). It still causes serious economic losses
(Diallo, 2003) and remains a major constraint on the development of small ruminant farms in these countries. PPR is considered to be one of the main constraints to improve productivity of small ruminants in the regions where it is endemic.

Thus its control is a major goal for programmes aim at poverty alleviation. Major outbreaks in Turkey and India in recent years have indicated a marked rise in the global incidence of PPRV (Bailey et al, 2005). It is of great economic importance on the basis of mortalities, morbidity, losses through body wastage, poor food efficiency, loss of meat, milk and milk products and offspring (Nawathe, 1984). A consequence of this high mortality was the inclusion of PPR in the list $A$ of the former animal disease classification of the OIE , the world organization for the Animal health. In the new OIE classification it is included in a group of economically important animal diseases, which must be notified to the Organization in all the regions where PPR is endemic.

There are four groups of phylogeny of which, 3 are located in Africa. The fourth group is the only one present into the Indian sub-continent but it also coexists in the Middle East with the East African group

\begin{tabular}{llll}
\hline 1. Assistant professor, & 2. & Associate Professor, \\
3. & Registrar, SDAU, Sardarkrushinagar, & 4. & SRF,AINP-Bluetongue, 5PG Scholar
\end{tabular}

www.veterinaryworld.org

Veterinary World Vol.2, No.4, April 2009 150 
Pesti des petits ruminants virus infection in animals

III . It was deduced that outbreaks in North and South India were caused by PPR viruses of different lineages and was suggested that either two viruses were independently introduced in India in the past decade or the South Indian virus has been enzootic infection in that region for many decades and was confused with $\mathrm{RP}$ virus, as before 1988 all Morbilli viruses infections were considered to be rinder pest. (Singh, 2002). The presence of the two African lineages in Asia beside a distinct Asian lineage may be taken as indication of the trade route of spread of the disease.

In India, PPR was first reported in 1987 from Arasur village in the Villapurum district of Tamilnadu, South India (Shaila et al, 1987). Since, its first reported occurrence in 1987, PPR was thought to be restricted to southern India up to 1993 , after which the epidemics of PPR swept away large number of small ruminants from Northern India (Nanda et al, 1996). Since, then the disease has been reported regularly from different parts of the country and is considered as an endemic disease causing a great loss to small ruminants of the country. Now the disease has spread all over India. In Gujarat, incidence of PPR was reported by various workers, namely , Hinsu et al, (2001), Tiwari (2005), Nagraj (2006), Sannat (2006) and Bulbule (2007).

It is still not clear whether the apparent geographical spread of the disease in the last 50 years is real or reflects increased awareness, wider availability of diagnostic tools or even a change in the virulence of the virus. It seems most likely that a combination of factors is responsible for the present knowledge of the disease distribution. It is also known that confusion of PPR with pneumonic pasteurellosis and other pneumonic diseases of small ruminants has precluded and delayed its recognition in some countries.

\section{Causative agent}

The etiological agent, Peste des petits ruminants virus (PPRV) virus has been classified under family Paramyxoviridae, Order Mononegavirales and Genus Morbillivirus (Tober et al, 1998). Similar to other morbilliviruses, PPRV is fragile and it can not survive for long time outside the host. Its half life has been estimated to be 2.2 minutes at $56^{\circ} \mathrm{C}$ and 3.3 hours at $37^{\circ} \mathrm{C}$ (Rossiter and Taylor, 1994).

Like other members of the family Paramyxoviridae, PPR virus is an enveloped pleomorphic particle. The genome of PPRV is single stranded RNA, approximately $16 \mathrm{~kb}$ long with negative polarity (Haas et al, 1995). PPR virions, as other morbilliviruses, are enveloped, pleomorphic particles containing single strand RNA as the genome. It is composed of 15, 948 nucleotides, the longest of all mobillivirus genomes sequenced so far. This genomic RNA is wrapped by the nucleoprotein $(\mathrm{N})$ to form the nucleocapsid into which are associated two other viral proteins: the phosphoprotein $(P)$ and the large protein $(L)$. the phosphoprotein is the cofactor of $L$, the viral RNA dependent RNA polymerase (RdRp). To the viral envelop which derives from the host cell membrane are associated three viral proteins: the matrix protein (M) which is located inside the envelope and serves as a link between the nucleocapsid and the two external viral proteins, the fusion protein $(F)$ and the haemmagglutinin $(\mathrm{H})$. By this position, M plays an important role in ensuring efficient incorporation of nucleocapsids into virions during the virus budding process. The haemagglutination allows the virus to bind to the cell receptor during the first step of the viral infection process. By their positions and their functions, both $\mathrm{F}$ and $\mathrm{H}$ are very important for the induction of protective host immune response against the virus. However $\mathrm{N}$ the most abundant and also the most immunogenic among PPRV proteins, does not induce protective immunity against the virus. It has been used in the development of diagnostic tests. (Diallo, 2007). Analysis of partial sequencing data of $\mathrm{N}$ gene has pointed out small variations between PPRV strains and has allowed their grouping into four lineages, which is better reflecting their geographical origins than the variations of genes of the external glycoproteins $F$ and $\mathrm{H}$.

\section{Host Range}

Epidemics in sheep and goats, the mainstay of subsistence farming in the developing world can cause mortality rates of $50-80 \%$ in naïve populations. Antelope and other small wild ruminant species can also be severely affected (Abu Elzein et al, 2004). A case of clinical disease has been reported in wildlife resulting in deaths of gazelles (Gazella dorcus), ibex (Capra ibex nubiana), gemsbok (Oryx gazelle) and Laristan sheep (Ovis orientalis laristanica). The American white tailed deer (Odocoileus virginianus) can be infected experimentally. (Hamdy and Dardiri, 1976). Cattle, buffaloes, camels and pigs can become infected but there is little or no evidence of disease associated with their infection. PPRV antigen has been detected in an outbreak of respiratory disease in camel and sick domestic buffaloes (Taylor et al, 1990; Scott, 2000; Abraham et al, 2005). In addition, PPRV is considered as a serious predisposing factor for respiratory disease complex in sheep and particularly in goats. (Taylor et al, 1990; Baily et al, 2005). Considering the immunosuppressive effect of PPRV as all other morbilliviruses, it may therefore be possible, depending on the age and physical state of 
Pesti des petits ruminants virus infection in animals

the host animal, that PPRV can occasionally overcome the innate resistance of large ruminants and lead to the development of clinical signs similar to rinder pest. (Diallo, 2007). This may explain the disease signs that had occurred in buffalo and camels following PPRV infection. This ability of PPRV to infect large ruminants could pose a serious threat to cattle populations in PPR endemic areas which, with the success of the global rinder pest eradication programme, are no longer vaccinated against rinder pest and so do not possess cross protective immunity against this virus. PPRV was isolated from RP like outbreak in Indian Buffaloes in Tamil Nadu where 50 out of 385 buffaloes were clinically affected. The infected buffaloes showed conjuctival congestion, profuse salivation and depression but none showed febrile response. The source of infection remained a mystery. (Govindrajan et al, 1997).PPRV was also suspected to be involved in the epizootic disease that affected one humped camels in Ethiopia in 1995-1996 (Rogers et al, 2001;). PPRV antigen and PPRV nucleic acid were detected in some pathological samples collected during that outbreak, but no live virus was isolated. It has received a growing attention because of its wide spread, economic impacts (Lefèvre and Diallo, 1990) and the role it plays in complication of the ongoing global eradication of rinderpest and epidemiosurveillance programmes (Couacy-Hymann et al., 2002).

\section{Transmission}

PPRV is transmitted by direct contact with secretions and excretions of infected animals. It is highly contagious and all discharges can carry virus. Substantial quantities of virus are found in ocular nasal or oral secretions of sick goats and in the faeces late in disease (Abegunde and Abu, 1977). Since the virus is enveloped, it is extremely sensitive to inactivation by environmental factors such as heat, sunlight and chemicals. It, therefore, require close contact with an infected animals for successful transmission. Pigs undergo silent infection by contact with infected goats but are unable to transmit the virus and are not regarded as important in the epidemiology of PPR (Nawathe and Taylor, 1979). Cattle may be infected without showing any clinical signs on experimental inoculation (Dardiri et al, 1976, Taylor and Abegunde, 1979). However, in poor conditions it might be possible that cattle develop lesions following PPRV infection, clinical signs of which would be ascribed to rinderpest. Indeed, in the 1950s, disease and death were recorded in calves experimentally infected with PPRV-infected tissue. (Mornet et al ;1956). PPRV was isolated from RP like outbreak in Indian Buffaloes in Tamil Nadu where 50 out of 385 buffaloes were clinically affected.
The infected buffaloes showed conjuctival congestion, profuse salivation and depression but none showed febrile response. The source of infection remained a mystery. (Govindrajan et al, 1997).PPRV was also suspected to be involved in the epizootic disease that affected one humped camels in Ethiopia in 1995-1996 (Rogers et al, 2001; Roger et al, 2000).PPRV antigen and PPRV nucleic acid were detected in some pathological samples collected during that outbreak, but no live virus was isolated.

\section{Pathogenesis}

PPR virus, like other morbilliviruses, is lymphotropic and epitheliotropic (Scott, 1981). Consequently, it induces the most severe lesions in organ systems rich in lymphoid and epithelial tissues. The respiratory route is the likely portal to entry. After the entry of the virus through the respiratory tract system, it localizes first replicating in the pharyngeal and mandibular lymph nodes as well as tonsil. Viremia may develop 2-3 days after infection and 1-2 days before the first clinical sign appears. Subsequently viremia results in dissemination of the virus to spleen, bone marrow and mucosa of the gastro-intestinal tract and the respiratory system (Scott, 1981).

\section{Clinical Signs}

The incubation period is about four days. The disease is particularly in young animals. Affected goats exhibit fever, dry muzzle and a serous nasal discharge which become mucopurulent. Erosions on the mucous membrane of the buccal cavity are accompanied by marked salivation. Ulcers develop in the mucosae of the alimentary, respiratory and urinary tracts. Conjuctivitis with ocular discharge is a feature of the disease. A profuse diarhhoea, which results in dehydration, develops within days of infection. Signs of tracheitis and pneumonia are common. There is a severe leucopenia which facilitates secondary bacteria infection.Pulmonary infections caused by Pasteurella species are common in the later stages of the disease.Pregnant animals may abort. Mortality rates in severe outbreaks often exceed $70 \%$ and actually affected goats may die within ten days of exposure to the virus. (Quinn et al, 2005; Forsyth and Barret,1995).

\section{Pathological Lesions}

Post mortem findings: The carcass of an affected animal is usually emaciated, the hindquarters soiled with soft/watery faeces and the eyeballs sunken. The eyes and nose contain dried-up discharges. Lips may be swollen; erosions and possibly scabs or nodules in late cases. The nasal cavity is congested (reddened) lining with clear or creamy yellow exudates and 
Pesti des petits ruminants virus infection in animals

erosions. They may be dry with erosions on the gums, soft and hard palates, tongue and cheeks and into the oesophagus. The lung is dark red or purple with areas firm to the touch, mainly in the anterior and cardiac lobes (evidence of pneumonia). Lymph nodes (associated with the lungs and the intestines) are soft and swollen. Abomasum congested with lining haemorrhages. The pathology caused by PPR is dominated by necrotizing and ulcerative lesions in the mouth and the gastro-intestinal tract (Roeder et al., 1994). Erosion in the oral cavity is a constant feature. The rumen reticulum and omasum rarely exhibit lesions. Occasionally, there may be erosions on the pillars of the rumen. The omasum is a common site of regularly outlined erosions often with oozing blood. Lesions in the small intestine are generally moderate, being limited to small streaks of hemorrhages and, occasionally, erosions in the first portions of the duodenum and the terminal ileum. The large intestine is usually more severely affected, with congestion around the ileo-cecal valve, at the ceco-colic junction and in the rectum. In the posterior part of the colon and the rectum, discontinuous streaks of congestion "zebra stripes" form on the crests of the mucosal folds. In the respiratory system, small erosion and petechiae may be visible on the nasal mucosa, turbinates, larynx and trachea. Bronchopneumonia may be present, usually confined to the anteroventral areas, and is characterized by consolidation and atelectasis.

Histopathology: PPR virus causes epithelial necrosis of the mucosa of the alimentary and respiratory tracts marked by the presence of eosinophilic intracytoplasmic and intranuclear inclusion bodies. Multinucleated giant cells (syncytia) can be observed in all affected epithelia as well as in the lymph nodes (Brown et al., 1991). In the spleen, tonsil and lymph nodes, the virus causes necrosis of lymphocytes evidenced by pyknotic nuclei and karyorrhexis (Rowland et al., 1971). Brown and others (1991) using immunohistochemical methods detected viral antigen in both cytoplasm and nuclei of tracheal, bronchial and bronchio-epithelial cell, type II pneumocytes, syncytial cells and alveolar macrophages. Small intestines are congested with lining haemorrhages and some erosions. Large intestines (caecum, colon and rectum) have small red haemorrhages along the folds of the lining, joining together as time passes and becoming darker, even green/black in stale carcasses.

\section{Diagnosis}

Definitive diagnosis of PPRV infection relies on laboratory techniques such as virus isolation, demonstration of PPRV antigen, viral nucleic acid and specific antibodies. The serological tests like AGID, CIEP etc. often fail to differentiate PPR from RP. The techniques available to differentiate PPR from RP are virus neutralization test, cDNA probes (Diallo et al, 1989), Virus specific monoclonal antibodies in an immunocapture enzyme linked immunosorbent assay (ELISA), (Libeau et al, 1994), Sandwich ELISA, PCR (Forshyth and Barrett, 1995) and haemagglutination using piglet or chicken (Shaila et al,1996) red blood cells. Similarly PPRV antibodies can be differentiated from RP antibodies by competitive ELISA (Libeau et al, 1995) and serum neutralization (Diallo et al, 1995) test. c-ELISA is rapid, sensitive and specific and most commonly used technique. RT-PCR test can be used as routine diagnostic tool for PPR diagnosis, which has good correlation with virus isolation (Brindha et al, 2001).

PCR in combination with nucleotide sequencing has made it method of choice for molecular characterization of viruses (Diallo, 1990). DNA sequence data of related viral genome can provide important information about functionally homologous proteins and can lead to better understanding of the molecular biology of viruses. Sequence analysis provides new insights into the interrelationship among lineages, members of the same genus and also with the members of other genus within the family. Therefore, it has become an important tool, not only in structural, but also in functional characterization of viruses. This kind of information is crucial in the logical design of marker vaccines or better diagnostic reagents (Dhar et al, 2002). Recently, full genome of wild type PPR virus (Turkey/2000) has been sequenced.

Differential Diagnosis: The disease must be differentially diagnosed from FMD, Bluetongue, contagious ecthyma, Pasteurellosis, CCPP etc.

\section{Prevention and Control}

Control of PPR outbreaks relies on movement control combined with the use of vaccine.

Proper disposal of carcass and contact fomites, decontamination and restriction on importation of sheep and goats from affected areas.

\section{Conclusion}

PPR is an important animal disease which now threatens the billion strong ruminants population in Africa, the Middle and Near East, South West and Central Asia. PPR is one of the priority animal diseases whose control is considered important for poverty alleviation in Western Africa and Southern Asia. Economic losses due to PPRV have been estimated to be 1800 million INR (US\$ 39 million) annually (Bandpadhyay, 2002). PPR is still a poorly recognized 
Pesti des petits ruminants virus infection in animals

disease, particularly with regard to epidemiological features such as transmission dynamics under different production systems. (Diallo, 2007). A population of goat and sheep in India is of 124.36 million 561.7 million respectively (http: dahd.nic.in/sheep.htm). The ratio of goat to sheep and the population intensity vary greatly under different agro climatic conditions. In India, sheep and goats play an important role in sustainable agriculture and employment generation (Anon, 2001; Anon, 2002).The mortality rate for the PPR is about $70-80 \%$, most animal dying within the 10-12 days following the onset of disease. a consequence of this high mortality was the inclusion of PPR in the list A of the former animal disease classification of the OIE (Office International des epizooties), the world Organisation for Animal health.. In the new OIE classification it is included in a group of economically important animal diseases, which must be notified to the Organisation in all the regions where PPR is endemic, it constitutes a serious threat to small ruminant production and there by influences on the livelihood of poor farmers, the main owner of sheep and goats. Thus its control is a major goal for programmes aims at poverty alleviation.

A great deal of more research into this aspect of the disease is urgently required. The fact that PPRV can infect cattle, buffaloes and camels, gives PPR an even higher priority, particularly in the current situation where vaccination against rinder pest in cattle has been stopped.

\section{References}

1. Abraham, G. et.al. (2005): Antibody seroprevalences against peste des petits ruminants virus in camels, cattle, goats and sheep in Ethiopia. Prev. Vet. Medicine. 70:51-57.

2. Asmar, J.A.et.al. (1980): A PPR-like disease of sheep in central Saudi Arabia: evidence of its immunologic relation to rinderpest; prospects for a control method. Proceedings of the Fourth Conference on the Biological Aspects of Saudi Arabia.University of Riyadh.; Riyadh; Saudi Arabia, 1980. pp. 325-337.

3. Barrett, T. et.al.(1993): The molecular biology of rinderpest and peste des petits ruminants. Ann. Med. Vet. 137 (2): 77-85.

4. Bailey, D. et. al. (2005): Full genome sequence of peste des petits ruminants virus, a member of the Morbillivirus genus. Virus Res. 110: 119-24.

5. Brindha, K.et.al.(2001): Comparison of virus isolation and polymerase chain reaction for diagnosis of peste des petits ruminants. Acta Virol. 45 (3): 169-172.

6. Couacy-Hymann, E. et.al. (2002): Rapid and sensitive detection of peste des petits ruminants virus by a polymerase chain reaction assay. $J$ Virol Methods. 100(1-2): 17-25.

7. Dhar, P. et.al. (2002): Recent epidemiology of PPRV.
Vet. Microbiol. 88: 153-159.

8. Diallo, A. (2003): Peste des petits ruminants. Featured article published in the website: http:// www.indiveterinarycommunity.com (Accessed 12th August, 2004).

9. Diallo, A.; Taylor, W. P.; Lefevre, P. C. and Provost, A. (1989): Attenuation d'une souche de virus de la peste des petits ruminants: candidat pour un vaccine homologue vivant (attenuation of a virulent PPR strain: potential homologous live vaccine) Rev Elev Med Vet Pays Trop. 42 : 311-319.

10. Ekue, N.F.; Tanya, V.N.; Ndi, C. and Saliki, J.T. (1992): A serological survey of antibodies against peste des petits ruminants (PPR) virus in small ruminants in Cameroon. Bulletin Anim. HIth. Prod. Afr. 40 (1): 49-53.

11. Forsyth, M.A; Barrett, T. (1995): Evaluation of polymerase chain reaction for the detection and characterisation of rinderpest and peste des petits ruminants viruses for epidemiological studies. Virus Res. 39(2-3):151-63.

12. George, A.A. (2002): Comparative evaluation of different gene targets for PCR diagnosis of PPR. M.V.Sc. thesis submitted to Deemed University IVRI, Izatnagar, India.

13. Govindarajan, R.; Koteeswaran, A.; Venugopalan, A.T.; Shyam, G.; Shaguna, S.; Shaila, M.S. and FRamachandran, S. (1997): Isolation of pestes des petits ruminants virus from an outbreak in Indian buffalo (Bubalus bubalis). Vet. Rec. 141: 573-574.

14. Hamdy, F.M.; Dardiri, A.H.; Nduaka, O.; Breese, S.R.Jr. and Ihemelandu, E.C. (1976): Etiology of the stomatitis pneumcenteritis complex in Nigerian dwarf goats. Can. J. Comp. Med. 40: 276-284.

15. Hinshu, T.V.; Kher, H.N.; Chandel, B.S. and Jhala, M.K. (2001): Seroprevalence of Peste des petits ruminants (PPR) in Gujarat. Indian J. Comp. Microbiol. Immunol. Infect. Dis. 22(1): 81.

16. Joshi, V. B.; Nagal, K. B.; Sharma, M.; Katoch, R. C.; Batta, M. and Sharma, A. K. (1996): Peste des petits ruminants (PPR) among gaddi sheep and goats in Himachal Pradesh. Ind J Anim Sci. 66:1126-1127.

17. Krishna, S .V.; Subharao, M.V and Shaila, M. S. (2001): Neutralising antibodies to peste des petits ruminants virus in small ruminants in Andhra Pradesh- A serological survey. Indian J. Anim. Sci. 71: 228-230.

18. Kulkarni, D.D.; Bhikane, A.U.; Shaila, M.S.; Varalakshmi, P.; Apte, M.P. and Narladkar, B.W. (1996): Peste des petits ruminants in goats in India. Vet. Rec. 138 (8): 187-188.

19. Kumar, P.; Kumar, R.; Sharma, A. and Tripathi, B.N. (2002): Pathology of peste des petits ruminants (PPR) in goats and sheep:spontaneous study. Indian J. Vet. Pathol. 26 (1-2):15-18.

20. Lefevre, P.C. and Diallo, A. (1990): Peste des petits ruminants virus. Rev. Sci. Tech. Off. Int. Epiz. 9: 951-965.

21. Lefevre, P. C.; Diallo, A., Schenkel, F.; Hussein, S. and Staak, G. (1991): Serological evidence of peste des petits ruminants in Jordan. Vet Rec. 128: 110.

22. Libeau, G.; Prehaud, C.; Lancelot, R.; Colas, F.; Guerre, 
Pesti des petits ruminants virus infection in animals

L.; Bishop, D.H.L. and Diallo, A. (1995): Development of a competitive ELISA for detecting antibodies to the peste des petits ruminants virus using a recombinant nucleoprotein. Res. Vet.Sci. 58 (1): 50-55.

23. Majiyagbe, K.A.; Nawathe, D.R. and Abegunde, A.(1992): Rapid diagnosis of PPR infection, application of immunoelectrophoresis (IEOP) technique. Rev. Elev. Med. et. Pays. Trop. 37: 11-15.

24. Misbah Aslam, Muhammad Abubakar, Rehana Anjum, Shamim Saleha, and Qurban Ali (2009): Prevalence of Peste Des Petits Ruminants Virus (PPRV) in Mardan, Hangu and Kohat District of Pakistan; Comparative Analysis of PPRV Suspected serum samples using Competitive ELISA (cELISA) and Agar Gel Immunodiffusion (AGID) Veterinary World 2(3) :89-92.

25. Nagraj (2006): Assessment of different gene target for detection of Peste des petits ruminants by RT-PCR and sequence analysis of $\mathrm{F}$ and $\mathrm{N}$ gene segments. M.V.Sc. thesis submitted to Anand Agricultural University, Anand, India.

26. Nanda, Y.P. et.al. (1996): The isolation of peste des petits ruminants virus from Northern India. Vet. Microbiol. 51 (3-4): 207-216.

27. Obi, T.U.; Ojo, M.O.; Taylor, W.P. and Rowe, L.W. (1983): Studies on the epidemiology of peste des petits ruminants in Southern Nigeria. Trop. Vet. 1(4): 209-217.

28. Ozkul, A. et.al. (2002). Prevalence, distribution, and host range of Peste des petits ruminants virus, Turkey. Emerging Infec. Dis. 8 (7): 708-712.

29. Patel, R.K. (2006): Seroepidemiological study of Peste des petits ruminants (PPR)virus in Sheep and Goats in North Gujarat. M.V.Sc. thesis submitted to Sardarkrushinagar Dantiwada Agricultural University, Sardarkrushinagar, India.

30. Purushothamum, V. et. al. (2006): An outbreak of peste des petits ruminants in small ruminants. Indian Vet. $J$. $83: 133-136$.

31. Raveendra Hegde,Amitha R. Gomes, S. M. Byre Gowda, Santhosh A. K and C. Renukaprasad (2009): Cytopathic effect of PPR vaccine virus strains in Vero cells. Veterinary World 2(3): 093-094.

32. Rita Narayanan, P.Gopu, S.Baegan and Bharathidasan (2008): Clinical Management in an outbreak of Peste Des Petits Ruminants in Barbari Goats. Veterinary
World 1 (3) : 81-82.

33. Roger, F.; Guebre, Y.M.; Libeau, G.; Diallo, A.; Yigezu, L.M. and Yilma, T. (2001): Detection of antibodies of rinderpest and peste des petits ruminants viruses (Paramyxoviridae, Morbillivirus) during a new epizootic disease in Ethiopian camels (Camelus dromedarius). Revue de Med. Vet. 152 (3): 265-268.

34. Roeder, P.L.; Abraham, G.; Kenfe, G. and Barrett, T. (1994): Peste des petits ruminants in Ethiopian goats. Trop. Anim. Hith. Prod. 26 (2): 69-73.

35. Rossiter, P.B and Taylor, W.P. (1994): Peste des petits ruminants. In infectious diseases of livestock. pp758. Eds. Coezter, J.A.W. Vol.II.

36. Sannat, C. (2006): Seroepidemilogy, isolation and characterization of PPRV in sheep and Goats of North Gujarat. M.V.Sc. thesis submitted to Sardarkrushinagar Dantiwada Agricultural University, Sardarkrushinagar, India.

37. Shaila, M.S.; Purashothaman, V.;Bhavsar, D.; Venugopal, K. and Venkatesan, R.A. (1989): Peste des petits ruminants of sheep in India. Vet. Rec. 125: 602 .

38. Shaila, M.S.; Shamaki, D.; Forsyth, M.A.; Diallo, A.; Goatley, L.; Kitching, R.P. and Barrett, T. (1996): Geographic distribution and epidemiology of peste des petits ruminants virus. Virus Res. $43(2): 149-53$.

39. Sharma C.S.; Misraullia K.S.; Shukla P.S. R.K.Bagherwal and Nidhi Singh (2007): Studies on determination of Peste des petits ruminants antibodies in goats by c-ELISA in Madhya Pradesh. Indian J.Field Vet.3:11-14.

40. Taylor, W.P.; Busaidy, S.A. and Barrett, T. (1990): The epidemiology of peste des petits ruminants in the Sultanate of Oman. Vet. Microbiol. 22 (4): 341-352.

41. Tiwari, A. (2005): Prevalence of Peste des petits ruminants (PPR) virus in small ruminants of Gujarat and its characterization by RT-PCR/ RFLP and SSCP profiles. M.V.Sc. thesis submitted to Anand Agricultural University, Anand, India.

42. Wamwayi, H. M., Rossiter, P. B., Kariuki, D. P., Wafula, J. S., Barrett, T. and Anderson, J. (1995): Peste des petits ruminants antibodies in East Africa. Vet. Rec. 136: 199-200.

\section{For free access of full text of past issues of Veterinary World please visit www. veterinaryworld.org. Full text of each issue of Veterinary World can be accessed from CABI website if your library has the subscription of CAB.}

